\title{
Assessment of astigmatism in manual and sutureless small incision cataract surgery
}

\author{
Ayena $\mathrm{KD}^{1 *}$, Billong $\mathrm{J}^{1}$, Vonor $\mathrm{K}^{1}$, Diallo JW ${ }^{2}$, Santos MAK ${ }^{1}$, Maneh $\mathrm{N}^{1}$, Nagbe $\mathrm{YE}^{1}$, Tete $\mathrm{Y}^{1}$ and Balo $\mathrm{K}^{1}$ \\ ${ }^{1}$ Faculté des Sciences de la Santé de l'Université de Lomé, Togo \\ ${ }^{2}$ Faculté des Sciences de la Santé de l'Université de Bobo-Dioulasso; Burkina Faso
}

\begin{abstract}
Introduction: Cataract surgery is experiencing progress and adaptations in recent years with the aim to obtain better anatomical and functional results. Extraction of cataract by phacoemulsification has become a gold standard with its multiple variants. In developing countries, the cataract surgery by manual and sutureless small incision technique (MSICS) is increasingly practiced. The aim of this study is to assess astigmatism before and after cataract surgery by MSICS.

Patients and methods: This is a descriptive, prospective and single-center study on cataract patients operated by temporal superior MSICS with insertion of a standard posterior chamber lens. Astigmatism was assessed preoperatively and postoperatively regularly for 3 months with an auto-refractometer.

Results: A total of 100 eyes of 100 patients met our inclusion criteria. The mean age was $62.34 \pm 11.21$ years. Visual acuity was reduced to blindness in $64 \%$ of cases and low vision in $36 \%$ before surgery. The mean preoperative astigmatism was $1.27 \pm 0.64 \mathrm{D}$. On day 90 postoperative (D90), visual acuity was greater than or equal to $3 / 10$ in $73 \%$ uncorrected and $91 \%$ with pinhole. The mean postoperative astigmatism was $0.90 \pm 0.60$ diopter at D90.

Discussion: The cataract surgery by MSICS offered in this small sample, a good vision in 91\% with a reduction of the power of the preoperative astigmatism without a modification of the axis.

Conclusion: Cataract surgery by temporal superior MSICS seems to offer good functional results with a reduction of astigmatism. MSICS technique would prepare eye surgeons for phacoemulsification. The insertion of an IOL after an ocular biometry will improve these preliminary results in patients operated by MSICS in developing countries where the demand of toric lenses is important.
\end{abstract}

\section{Introduction}

According to the World Health Organization (WHO), cataract is the leading cause of blindness in the world [1]. It constitutes $50 \%$ of all causes of preventable blindness. Developing countries are paying a heavy price. The only treatment is surgery. This one has benefited from many technological and technical advances, ranging from intra-capsular extraction to Femtosecond laser surgery through phacoemulsification. The latter gives good functional results, but is very expensive, especially for developing countries. In recent decades, a new technique has emerged, looking like phacoemulsification but without the use of ultrasound [2]. It is the surgical technique of cataract named sutureless and manual small incision cataract surgery (MSICS). It also gives good anatomical and functional results [2-8]. The purpose of this study was to assess the corneal astigmatism after cataract surgery by MSICS.

\section{Patients and methods}

We conducted a prospective and descriptive study in a confessional ophthalmological hospital located in Togo, in the plateau region, 135 $\mathrm{km}$ from Lome, on the main road called "National Number 1 ".

Our study covered a period of 14 months, from September 2012 to October 2013. Were included in this study, patients aged at least 40 years old, who showed an operable cataract with normal photomotor reflex and operated by the MSICS technique, on the temporal superior site. These patients should also honor their postoperative check-up visits up to the ninetieth day. Were not included in our study, patients operated on for traumatic cataract, and those who had on preoperative examination, a history or other eye diseases which could strain the visual prognosis or induce astigmatism, such as pterygium, corneal scars. The visual acuity with pinhole was considered as blindness when it was less than $1 / 20$, low vision when ranged between $1 / 20$ and less than $3 / 10$, and good vision when it was greater than or equal to $3 / 10$.

Preoperatively as well as postoperatively, all our patients had a complete ophthalmological examination and an objective refraction on an auto-refractometer without cycloplegia. Postoperative control was made on the $3^{\text {rd }}, 17^{\text {th }}, 47^{\text {th }}, 77^{\text {th }}$ and $90^{\text {th }}$ days. Astigmatism was classified as not significant when its refractive power was lower in absolute value than one diopter and significant when its power was greater than or equal to in absolute value one diopter. Considering the axis of astigmatism registered in negative cylinder by the auto-refractomter, it was classified as direct when its value was $0^{\circ} \pm 30^{\circ}$, indirect when it was $90^{\circ} \pm 30^{\circ}$ and oblique when it was $45^{\circ} \pm 15^{\circ}$ or $135^{\circ} \pm 15^{\circ}$.

Correspondence to: AYENA Koffi Didier, 08 BP 8986 Lomé, Togo, Tel: 0022822 1973 58, Fax: 00228222260 82; E-mail: didier23fr@yahoo.fr

Keywords: lens, cataract surgery, Africa

Received: October 03, 2015; Accepted: October 24, 2015; Published: October 27,2015 
As for the surgery, they were done by the same surgeon with an experience of more than 2,000 cataract surgeries by MSICS under the same conditions.

The surgical approach was made by a tunneled eyebrow temporal superior scleral incision of $6 \mathrm{~mm}$ length which peak was at $2.5 \mathrm{~mm}$ from the limbus. The peribulbar anesthesia using 5 to $8 \mathrm{ml}$ of $2 \%$ lidocaine with epinephrine was performed a few minutes before the start of surgery. The implants inserted were of standard power of 21 or 22 diopters depending on what was available since no implant power calculation was made prior to surgery. The residual astigmatism was calculated by the difference between the power of the pre- and postoperative astigmatism at each check-up visit. Each participant gave consent before being recruited for the study.Our results were analyzed using the Epi Info 7.0.

\section{Results}

A total of 100 eyes of 100 patients were included in 51 women and 49 men corresponding to a sex ratio of 0.96 . The age varied between 40 and 100 years with a mean of $62.34 \pm 11.21$ years. The most represented age groups were those of 60-69 years and 50-59 years respectively with a frequency of $35 \%$ and $26 \%$. Female gender was predominant in most represented age groups (Figure 1).

The far preoperative visual acuity with pinhole was blindness in $64 \%$ of cases and low vision in $36 \%$ (Figure 2 ). We got $81 \%$ of posterior sub-capsular cataracts and $19 \%$ of corticonuclear. The operated eye was right in $51 \%$ of cases and left in $49 \%$.

The far postoperative visual acuity with pinhole was blindness in

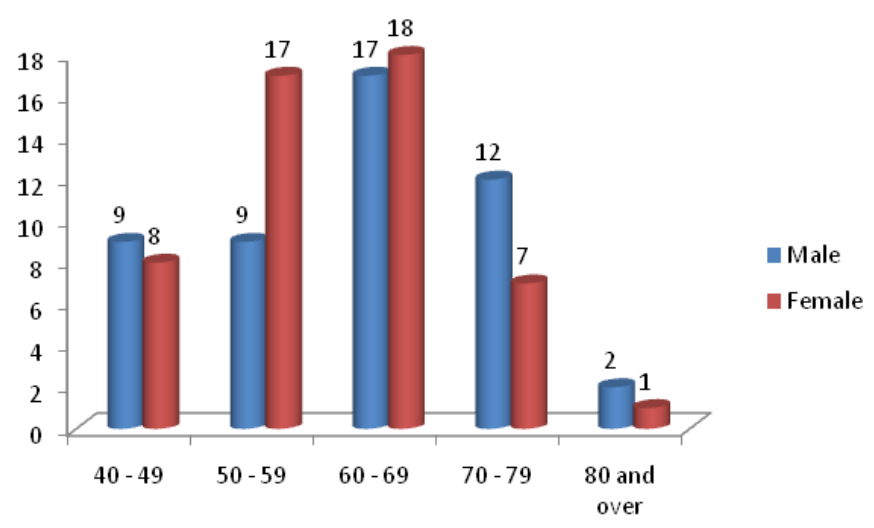

Figure 1. Patients repartition according to age and gender.

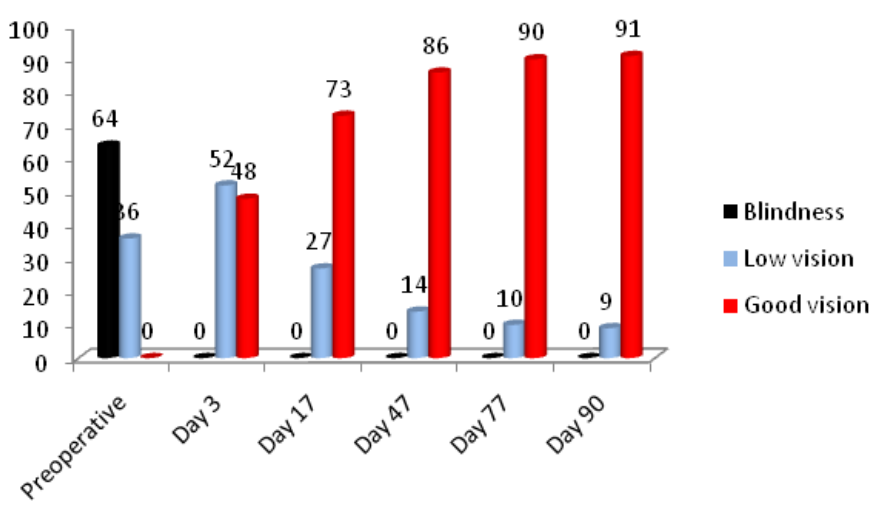

Figure 2. Pin hole visualacuty repartition of eyes before and after surgery. zero case, low vision which gradually decreased from $52 \%$ to $9 \%$ and good vision which increased steadily from $48 \%$ to $91 \%$ respectively from the third day to the third months (Figure 2). Good vision without correction was observed in $73 \%$ of cases. The patients had a far visual acuity with pinhole greater than $5 / 10$ in $83 \%$ on the third postoperative month.

Preoperatively, astigmatism was not significant in $36 \%$ and significant in $64 \%$ with an average which was $1.27 \pm 0.64$ diopter (Table 1). Similarly postoperative astigmatism was not significant in $55 \%$ and significant in $45 \%$. The mean value of postoperative astigmatism gradually decreased from $1.22 \pm 0.60 \mathrm{D}$ to $0.90 \pm 0.60 \mathrm{D}$ respectively from the third to the ninetieth day (Table 1). As far as the axis are concerned, preoperative astigmatism was indirect in $48 \%$ of cases and direct in 36\% (Table 2). Postoperatively, astigmatism was indirect in $56 \%$ of cases at D90 (Table 2). The mean power of the residual astigmatism gradually decreased from $0.77 \pm 0.52 \mathrm{D}$ on the 3rd postoperative day to $0.53 \pm 0.40 \mathrm{D}$ on the 90 th postoperative day (Table 3).

We recorded two cases of hyphema grade 1 peroperatively. In the postoperative period, we observed one case of hyphema grade 1 and a central corneal edema 1 plus that disappeared in the second monitoring visit.

\section{Discussion}

The extracapsular cataract extraction by MSICS is increasingly practiced in Togo since 2010. This technique allows to work in a self-sealing anterior chamber. The postoperative astigmatism is a complication of cataract surgery [5-8]. The authors wanted to assess astigmatism in this recent technique. In this respect, they conducted a single-center prospective and descriptive study of 100 eyes. Other authors have conducted similar studies in developing countries [2,3,5-8].

In our working contexts characterized by a late consultation, lack of phacoemulsifier and social coverage and the low purchasing power of the population, the authors had but the option to perform the cataract extraction with the MSICS technique. Other authors have also preferred this technique in similar conditions [5-9].

Female gender was slightly more represented than male with a sex ratio $(\mathrm{M} / \mathrm{F})$ of 0.96 . Many authors also observed a feminine predominance in their studies $[3,10,11]$. Our results can be explained by the greater representation of females in the general population of the country especially when age advances in the direction of statistics and demography.

The mean age in our study was $62.34 \pm 11.21$ years. Our results are similar to those of Adio et al.[12] in Nigeria (61.06 \pm 15.99 years) and Bhallil et al.[13] Morocco (62 \pm 10.84 years).

Preoperative visual acuity was blindness in $64 \%$. This characterizes developing countries. In a study of preoperative visual acuity, which brought together 50 countries of different levels of development, Shah et al. [14] reported that $47 \%$ of patients operated on for cataracts in poor countries were blind, against only $1 \%$ in developed countries.

Postoperatively all patients had their sight restored with low vision which had declined from $48 \%$ to $9 \%$ and good vision which improved from $52 \%$ to $91 \%$ respectively from the $3^{\text {rd }}$ to the $90^{\text {th }}$ day. WHO recommends that $80 \%$ of operated eyes have a good vision [15]. The implant power calculation and thus the insertion of an adequate IOL power, rather than the standard implant could have improved the rate 
Table 1. Eyes repartition according to astigmatism power in diopter (D).

\begin{tabular}{|c|c|c|c|c|c|c|}
\hline \multirow[b]{2}{*}{ Power } & \multirow[t]{2}{*}{ Preoperative (\%) } & \multicolumn{5}{|c|}{ Postoperative (\%) } \\
\hline & & D3 & D17 & D47 & D77 & D90 \\
\hline$[2.00 ; 3.50]$ & 21 & 18 & 15 & 12 & 7 & 7 \\
\hline$[1.00 ; 2.00]$ & 43 & 47 & 51 & 47 & 42 & 38 \\
\hline$[0 ; 1.00]$ & 36 & 35 & 34 & 41 & 51 & 55 \\
\hline Average & $1.27 \pm 0.64$ & $1.22 \pm 0.60$ & $1.00 \pm 0.60$ & $1.00 \pm 0.60$ & $0.90 \pm 0.60$ & $0.90 \pm 0.60$ \\
\hline
\end{tabular}

$\mathrm{D}=$ Day $;(\%)=$ percentage

Table 2. Eyes repartition according to astigmatism axis.

\begin{tabular}{|l|c|c|c|c|c|}
\hline & Preoperative (\%) & \multicolumn{3}{|c|}{ Postoperative (\%) } \\
\hline Axis & & J3 & J17 & J47 & J77 \\
\hline With the rule astigmatism & 36 & 29 & 30 & 29 \\
\hline Against the rule astigmatism & 48 & 55 & 55 & 55 & 50 \\
\hline Oblique astigmatism & 16 & 16 & 15 & 16 & 56 \\
\hline
\end{tabular}

$\mathrm{D}=$ day $;(\%)=$ percentage

Table 3. Eyes repartition according to induced astigmatism power in diopter.

\begin{tabular}{|l|c|c|c|c|}
\hline Power & D3 (\%) & D17 (\%) & D47 (\%) & D77 (\%) \\
\hline$[2,00 ; 3,50]$ & 3 & 1 & 0 & 0 \\
\hline$[1,00 ; 2,00]$ & 33 & 29 & 15 & 11 \\
\hline$[0 ; 1,00]$ & 64 & 70 & 85 & 89 \\
\hline Average & $0.77 \pm 0.52$ & $0.70 \pm 0.52$ & $0.57 \pm 0.52$ & $0.53 \pm 0.40$ \\
\hline
\end{tabular}

$\mathrm{D}=$ day; $(\%)=$ percentage

of good vision recovery after surgery. Ruit et al. [5] and VanZyl et al. [16] reported $98 \%$ and $83 \%$ of good vision in Nepal and Australia in the third and sixth months respectively. It would be interesting that each cataract surgery center have a biometer and a good range of implants in developing countries.

Preoperatively, 64\% of eyes were bearing a clinically significant astigmatism. The mean preoperative astigmatism was $1.27 \pm 0.64 \mathrm{D}$. These results are higher than those reported by Gokhale et al. [17] in their work on the manual and sutureless small incision cataract surgery (MSICS) and the induction of astigmatism that was $0.50 \mathrm{D}$. Our results are similar to those of Isyaku et al.[18] in Nigeria who reported a mean astigmatism of $1.16 \mathrm{D}$. Also, the axis of preoperative astigmatism was indirect in $48 \%$ of cases. Our results are similar to those of some authors who have found that most senile cataract patients have an indirect astigmatism whose incidence increases with age, especially after 50 years [19-23]. Sanfilippo et al. [21] reported a mean frequency of significant astigmatism among those aged 70 and over in $55.1 \%$ with extremes of 47.2 and $62.7 \%$. The frequency of significant indirect astigmatism was $56.66 \%$ in Nigeria [18].

Postoperative astigmatism was significant in $45 \%$ (Table 1) and indirect in $56 \%$ (Table 2 ). The mean astigmatism decreased gradually from $1.22 \pm 0.60 \mathrm{D}$ to $0.90 \pm 0.60 \mathrm{D}$ from the $3 \mathrm{rd}$ to the 90 th day. These results are similar to those of Kongsap et al. [24] who obtained a mean postoperative astigmatism of $0.87 \pm 0.62 \mathrm{D}$ on the 90th postoperative day. Magdun et al. [25] reported that the upper scleral incision had induced an indirect astigmatism. Yuan et al. [26] observed a significant postoperative astigmatism in $79.24 \%$ which was indirect in $52.41 \%$ of cases in the north of China. We can infer from our results that the potential demand for toric implant is important in our patients to improve the visual acuity without a postoperative correction.

The mean of induced astigmatism was $0.77 \pm 0.52 \mathrm{D}$ at D3 and decreased gradually to $0.53 \pm 0.40 \mathrm{D}$ at D90. Kongsap et al. [24] reported in 2011 in a comparative study of the modified Blumenthal technique and that of Ruitmodified a respective average induced astigmatism of $0.55 \mathrm{D} \pm 0.45$ and $0.50 \pm 0.44 \mathrm{D}$. However, Gokhale et al.[17] reported that the upper scleral incision induced approximately $1.28 \mathrm{D}$ astigmatism. The upper scleral incision was located $1.5 \mathrm{~mm}$ from the limbus in the study of Gokhale while it was located $2.5 \mathrm{~mm}$ from the limbus in our series. According to Malik et al. [19], the farther the incision from the visual axis, the less induced astigmatism. This is the reason why the temporal approach is the best site to minimize induced astigmatism [19,25]. Furthermore, Burgansky et al.[27] have studied the relationship between the size of the incision and the mean value of induced astigmatism. A $6 \mathrm{~mm}$ incision induced a mean astigmatism of $0.6 \pm 0.3 \mathrm{D}$. Our results are close to that forecast. We will conduct a study of induced astigmatism in the superior temporal incision to compare our current results later.

\section{Conclusion}

Cataract surgery by MSICS technique appears to offer good functional results with a reduction of astigmatism when the incision is made in temporal superior approach. The insertion of an IOL after eye biometrics will improve these preliminary results in patients operated for cataract by MSICS in developing countries. The potential demand in toric implant is high. A comparative study of MSICS and ECCE seems necessary. 


\section{References}

1. Foster A, Gilbert C, Johnson G (2008) Changing patterns in global blindness: 19982008. Comm Eye Health J 21: 37-9. [Crossref]

2. Ndiaye PA, El Amary K, Seye-Ndiaye C, Demeideros M, Wane A-M, et al. (1999) Mini-incision sclérale sans ultrasons dans le traitement de la cataracte congénitale. $J$ Fr Ophtalmol 22: 347-51.

3. Ang M, Evans JR, Mehta JS (2012) Manual small incision cataract surgery (MSICS) with posterior intraocular lens versus extracapsular cataract extraction (ECCE) with posterior intraocular lens for age-related cataract. Cochrane Database Syst Rev 14: 14-5. [Crossref]

4. Muhammad TK, Sanaullah J, Zakir H, Samina K, Muhammad KK, et al. (2010) Visual outcome and complications of manual sutureless small incision cataract surgery. Pak J Ophthalmol 26: 32-8.

5. Ruit S, Tabin G, Chang D, Bajracharya L, Kline DC, et al. (2007) A prospective randomized clinical trial of phacoemulsification $v s$. manual sutureless small-incision extracapsular cataract surgery in Nepal. Am J Ophthalmol 143: 32-8. [Crossref]

6. Sherwin JC, Dean WH, Schaefers I, Courtright P, Metcalfe N (2012) Outcomes of manual small-incision cataract surgery using standard 22 dioptre intraocular lenses at Nkhoma Eye Hospital, Malawi. Int Ophthalmol 32: 341-7. [Crossref]

7. Tabin G, Chen M, Espandar L (2008) Cataract surgery for the developing world. Curr Opin Ophthalmol 19: 55-9. [Crossref]

8. Gogate PM, Deshpande M, Wormald RP, Kulkarni SR (2003) Extracapsular cataract surgery compared to manual small incision cataract surgery in community eye care setting in western India: a randomized controlled trial. Br J Ophthalmol 87: 667-72. [Crossref]

9. Jongsareejit A, Saenghirun S (2014) An innovation of manual small incision cataract surgery (MSICS): a technique for advanced cataract disease in Thailand. J Med Assoc Thai 97: 1177-81. [Crossref]

10. Riaz Y, Mehta JS, Wormald R, Evans JR, Foster A, et al. (2006) Surgical interventions for age-related cataract. Cochrane Database of Systematic Reviews 2006; 4: 5-6. [Crossref]

11. Lindfield R, Kuper H, Polack S, Eusebio C, Mathenge W, et al. (2009) Outcome of cataract surgery at one year in Kenya, the Philippines and Bangladesh. Br J Ophthalmol 93: 875-80. [Crossref]

12. Adio AO, Aruotu N (2011) Induced astigmatism after cataract surgery - a retrospective analysis of cases from the University of Port Harcourt Teaching Hospital, Nigeria. $S$ Afr Optom 70: 75-80.

13. Bhallil S, Benatiya AI, Chraibi F, Tahri H (2009) Évolution à long terme de l'astigmatismeinduit après phacoémulsificationréaliséeencornéeclaire: incision 3.2 mm. J Fr Ophtalmol 32: 110.

14. Shah SP, Gilbert CE, Razavi H, Turnerb EL, Lindfield J (2011) Preoperative visua acuity among cataract surgery patients and countries' state of developpement: a global study. Bull World Health Organ 89: 749-56. [Crossref]

15. Hennig A (2005) Chirurgie de la cataracte sans suture et sans phacoémulsification: une solution pour réduire la cécité par cataractedans le monde? RSOC 2: 4 - 5.

16. Van Zyl L, Kahawita S, Goggin M (2014) Manual small incision extracapsular cataract surgery in Australia. Clin Experiment Ophthalmol 42: 729-33. [Crossref]

17. Gokhale NS, Sawhney S (2005) Reduction in astigmatism in manual small incision cataract surgery through change of incision site. Ind J Ophthalmol 53: 201-3. [Crossref]

18. Isyaku M, Ali SA, Hassan S (2014) Preoperative corneal astigmatism among adult patients with cataract in Northern Nigeria. Indian J Ophthalmol 62: 1094-5. [Crossref]

19. Malik VK, Kumar S, Kamboj R, Jain C, Jain K (2012) Astigmatism following manual small incision cataract surgery. Nepal J Ophthalmol 4: 54-8.

20. Lyle WM (1971). Changes in corneal astigmatism with age. Am J Ophthalmol 48: 467-78.

21. Sanfilippo PG, Yazar S, Kearns L, Sherwin JC, Hewitt AW, et al. (2015) Distribution of astigmatism as a function of age in an Australian population. Acta Ophthalmol 93: e377-85. [Crossref]

22. Cui Y, Meng Q, Guo H, Zeng J, Zhang H, et al. (2014) Biometry and corneal astigmatism in cataract surgery candidates from Southern China. J Cataract Refract Surg 40: 1661-9. [Crossref]

23. Lyall DA, Srinivasan S, Ng J, Kerr E (2014) Changes in corneal astigmatism among patients with visually significant cataract. Can J Ophthalmol 49: 297-303. [Crossref]

24. Kongsap P (2011) Visual outcome of manual small incision cataract surgery: comparison of modified Blumenthal and Ruit techniques. Int J Ophthalmol 4: 62-5. [Crossref]

25. Magdum RM, Gahlot A, Maheshgauri RD, Patel K (2012) A comparative study of surgically induced astigmatism in superior and temporal scleral incision in manual small incision cataract surgery. Natl J Med Res 2: 497-500.

26. Yuan X, Song H, Peng G, Hua X, Tang X (2014) Prevalence of corneal astigmatism in patients before cataract surgery in northern China. J Ophthalmol. 536412,publiéenligne 3 juin 2014 doi: 10.1155/2014/536412.

27. Burgansky Z, Isakov I, Avizemer H, Bartov E (2002) Minimal astigmatism after sutureless planned extracapsular cataract extraction. J Cataract Refract Surg 28: 499503. [Crossref]

Copyright: (C2015 Ayena KD. This is an open-access article distributed under the terms of the Creative Commons Attribution License, which permits unrestricted use, distribution, and reproduction in any medium, provided the original author and source are credited. 